\title{
Cost-utility of stereotactic radiation therapy versus proton beam therapy for inoperable advanced hepatocellular carcinoma
}

\author{
Henry W.C. Leung ${ }^{1,2}$ and Agnes L.F. Chan ${ }^{2,3}$ \\ ${ }^{1}$ Department of Radiation Oncology, An Nan Hospital, China Medical University, Tainan, Taiwan \\ ${ }^{2}$ Department of Nursing, Min-Hwei College of Health Care Management, Tainan, Taiwan \\ ${ }^{3}$ Department of Pharmacy, An Nan Hospital, China Medical University, Tainan, Taiwan \\ Correspondence to: Agnes L.F. Chan, email: agnes.If@gmail.com \\ Keywords: proton beam, SBRT, ICER, NMB, WTP \\ Received: October 24, $2016 \quad$ Accepted: April 11,2017 Published: April 21, 2017 \\ copyright: Leung et al. This is an open-access article distributed under the terms of the Creative Commons Attribution License 3.0 (CC BY \\ 3.0), which permits unrestricted use, distribution, and reproduction in any medium, provided the original author and source are credited.
}

\section{ABSTRACT}

The cost-utility of proton beam therapy was compared to stereotactic body radiation therapy for inoperable advanced hepatocellular carcinoma. A Markov decision-analytic model was performed following time to progression and survival using phase II trial data. Patients transitioned between three health states. Clinical outcomes were estimated for quality of life using utility estimates in the published literature and measured as incremental cost-effectiveness ratios (ICERs) and net monetary benefits (NMBs). Real direct medical costs were extracted from the Bureau of National Health Insurance database. One-way and probabilistic sensitivity analyses assessed the impact of specific variables on the model. In the base-case scenario, the modeled median survival was 16 months for proton beam therapy and 10 months for SBRT. Proton beam therapy resulted in an additional 2.61 quality-adjusted life years (QALYs) at an incremental cost of NT\$557,907 compared to SBRT. The ICER was NT\$213,354 per QALY gained. The probabilistic sensitivity analysis predicted a $97 \%$ chance of proton beam therapy being cost-effective at the willingness to pay NT\$2,157,024 per QALY gained. Thus, proton beam therapy is a cost-effective therapy for inoperable advanced hepatocellular carcinoma at the willingness-to-pay threshold of Taiwan.

\section{INTRODUCTION}

Approximately $80 \%$ of all liver cancers are hepatocellular carcinoma (HCC), a primary malignant neoplasm derived from hepatocytes. HCC was the leading cause of cancer death worldwide in 2012, and the second leading cause of cancer death in Taiwan in 2014 [1,2]. The HCC incidence rate is higher in men than in women and nearly $50 \%$ of all cases and deaths are reported in China [3]. The 5-year survival rate for patients diagnosed with HCC is exceedingly poor at 3-5\% [4]. For inoperable advanced HCC (mHCC), the 1-year median survival rate is $20-30 \%$ [5-6].

For patients with small inoperable HCC $(\leq 5$ $\mathrm{cm}$ diameter), local ablative treatments, such as transcatheter arterial chemoembolization (TACE) and radiofrequency ablation, achieve excellent local control
[7]. However, treatment of large HCC ( $\geq 7 \mathrm{~cm}$ diameter) is still challenging, as no standard treatment strategy is available. Modern radiation therapy includes stereotactic body radiotherapy (SBRT) which has been used for large mHCC [8-12]. A prolonged median overall survival of 17 months and 31 months was reported by two phase II clinical trials $[8,9]$. However, the use of these modern radiation therapies has high treatment costs, though no study has assessed whether the clinical benefits may offset the increased cost. The objective of the present study was to compare the cost-utility of PBT and SBRT for patients with $\mathrm{mHCC}$ from the perspective of a single payer healthcare system. 


\section{MATERIALS AND METHODS}

\section{Clinical data sources}

We performed a systematic literature search of the PubMed database to identify all randomized controlled trials (RCTs) of PBT or SBRT for inoperable advanced HCC performed from January 1, 1999, to September 31, 2016. The search strategy was based on combinations of ("unresectable" or "inoperable" or "advanced" or "metastatic" hepatocellular carcinoma" [Mesh]) and (SBRT or proton [Mesh] ) ("randomized controlled trials" or" clinical trials" [Mesh]). We also searched costeffectiveness studies using the medical subject headings or key words: quality-adjusted, QALY, life-year gained, and cost-effectiveness. Two reviewers (AC and HL) were responsible for independently evaluating the appropriate full text with reference to the same inclusion and exclusion criteria. RCTs or clinical studies published in English regarding the treatment of $\mathrm{mHCC}$ by PBT or SBRT were included. Letters to the editor, case reports, nonrandomized trials, animal studies, editorials, and posters were excluded. Any discrepancies between reviewers were resolved by consensus. We finally selected one phase I/II RCT of SBRT and one phase II study of PBT for mHCC as the clinical data source for the model.

\section{Markov model}

A Markov model was constructed using TreeAge Pro2014 Suite (R1.0 Released; TreeAge Inc., Williamstown, MA) to evaluate the costs, health outcomes, and cost-effectiveness of PBT versus SBRT in the treatment of mHCC. In the base case analyses, the model simulated a hypothetical cohort of 10,000 patients and repeated 1,000 times for each of the two treatment regimens. The time horizon of the model was 5 years (60 months). We hypothesized three health states: stable disease, disease progression and death in the model according to the phase I/II clinical trials, the phase II trial and the expert opinions $[8,9]$ (Figure 1). A patient in the model was considered to be in one of the three health states at any time. All patients began in the stable stage and transitioned from one state to another on the basis of the transition probabilities; they received either SBRT or PBT. In the model, we did not include deaths from natural causes that occurred in any health state. Death from cancer was assumed to occur after disease progression. The model perspective was based on the Bureau of National Health Insurance (BNHI) in Taiwan, with a 1-month cycle length adjusted to half-cycle in each health state process. The willingness-to-pay (WTP) threshold was defined by the World Health Organization (WHO) as 3-times the per capita gross domestic product (GDP) $[13,14]$.
The Taiwan per capita GDP in 2016 was NT\$719,008 (US\$22,469) [15]; therefore, the WTP threshold was considered to be NT\$2,157,024/QALY. A panel of local experts (blood oncologist, radiation oncologist, and one expert in pharmacoeconomic analysis) was consulted to ensure that the assumptions in the model reflected routine clinical practice.

\section{Treatment regimen}

Our treatment schema and outcomes were modeled from the phase I/II SBRT study and phase II PBT study [8, 9]. According to expert opinion, the total radiation dose, patterns of treatment failure, and patient survival were assumed to be the same as in the studies. According to the phase I/II trial, the SBRT treatment regimen doses were 30 to 54 Gy (24 to 54 Gy in Trial 1) in six fractions every other day over 2 weeks, delivered to the planning target volume (PTV). The dose to tumor vascular thrombosis plus PTV margin could be limited to $30 \mathrm{~Gy}$. The PBT regimen had a total dose ranging from 50 Gy in 10 fractions to 87.5 Gy in 30 fractions (median, 72 Gy in 16 fractions) and was administered without serious acute and late adverse events. All patients received PBT to a total dose of 76 Gy for 5 weeks in once daily 3.8-Gy fractions four days a week using a 150 to $190 \mathrm{MV}$ proton beam. Detailed treatment was mentioned in two clinical trials. The severe toxicities ( $\geq$ grade 3 ) necessitating treatment were considered in our model.

\section{Probabilities and utilities}

The transition probabilities of the health states were estimated using the equation published previously: $\mathrm{P}(1$ month $)=1-(0.5)^{(1 / \text { median time to event })}[16-18]$. Health state utilities were reduced according to the incidence rate of the severe adverse event ( $\geq$ grade 3 ) reported in the two clinical trials.

\section{Direct medical costs}

The direct health care medical costs were extracted from the BNHI database in 2016, including drug costs, laboratory test, physician visits, pharmacy dispensing fees, and treatment costs for grade 3/4 adverse events. Based on a policy issued by the BNHI, the reimbursement cost for SBRT is approximately NT $\$ 213,660$ as a treatment package. We also assumed that the PBT was reimbursed at NT $\$ 300,000$ as a package, which is now paid by the patients for the treatment of mHCC. All costs have been discounted at a real annual rate of $3 \%$ to adjust for the relative value of the Taiwan dollar. 
Table 1: Estimated cost inputs used in the model

\begin{tabular}{|l|l|l|}
\hline \multicolumn{2}{|c|}{ Cost input } & \multicolumn{2}{l|}{ Value } \\
\hline Costs (NT\$) & Proton & SBRT \\
\hline Treatment cost & 300,000 & 213,660 \\
\hline Costs of laboratory test, CT & 0 & 12982 \\
\hline Sub-total of PFS stage & $\mathbf{3 0 0 , 0 0 0}$ & $\mathbf{2 2 6 , 6 4 2}$ \\
\hline Costs of laboratory test, CT & 94000 & 82,801 \\
\hline Treatment cost for toxicity & 6493 & 63,054 \\
\hline Sub-total of PD stage per visit & $\mathbf{1 0 0 4 9 3}$ & $\mathbf{1 4 6 , 3 0 5}$ \\
\hline Total & $\mathbf{4 0 0 4 9 3}$ & $\mathbf{3 7 2 9 4 7}$ \\
\hline
\end{tabular}

Abbreviation: PFS, progression free survival; PD, progression disease, CT, computerized tomography; SBRT, stereotactic body radiotherapy

\section{Cost-utility analysis}

Cost-utility was evaluated using the incremental cost-effectiveness ratio (ICER) and net monetary benefit (NMB) method. ICERs were calculated as the ratio of the difference in total direct medical costs to the difference in QALYs [19]. The NMB approach was changed in various WTP thresholds. NMB is defined as $\Delta \mathrm{E} \lambda-\Delta \mathrm{C}$, where $\lambda$ is the WTP per QALY threshold, $\triangle \mathrm{E}$ is the effectiveness, and $\triangle \mathrm{C}$ is the incremental cost of two treatments. NMB regression analyses were modeled to compare SBRT with PBT based on varying the threshold value from NT\$0.00 to NT\$2,157,024 [20]. When the NMB value of the regimen was positive at a specific WTP value, we hypothesized that the regimen was cost-effective at the WTP value.

\section{Sensitivity analysis}

A tornado diagram was conducted to determine the major parameters impacting the model. The probabilistic sensitivity analysis was performed using a Monte Carlo simulation based on 10,000 samples by varying all parameters over a range of $\pm 30 \%$ in relation to the base-case data in the model simultaneously (Table 2) . The distributions for each parameter in the probabilistic sensitivity analysis were modeled. Lognormal distributions were adopted for all costs, and beta distributions were adopted for probabilities, utilities, and toxicity.

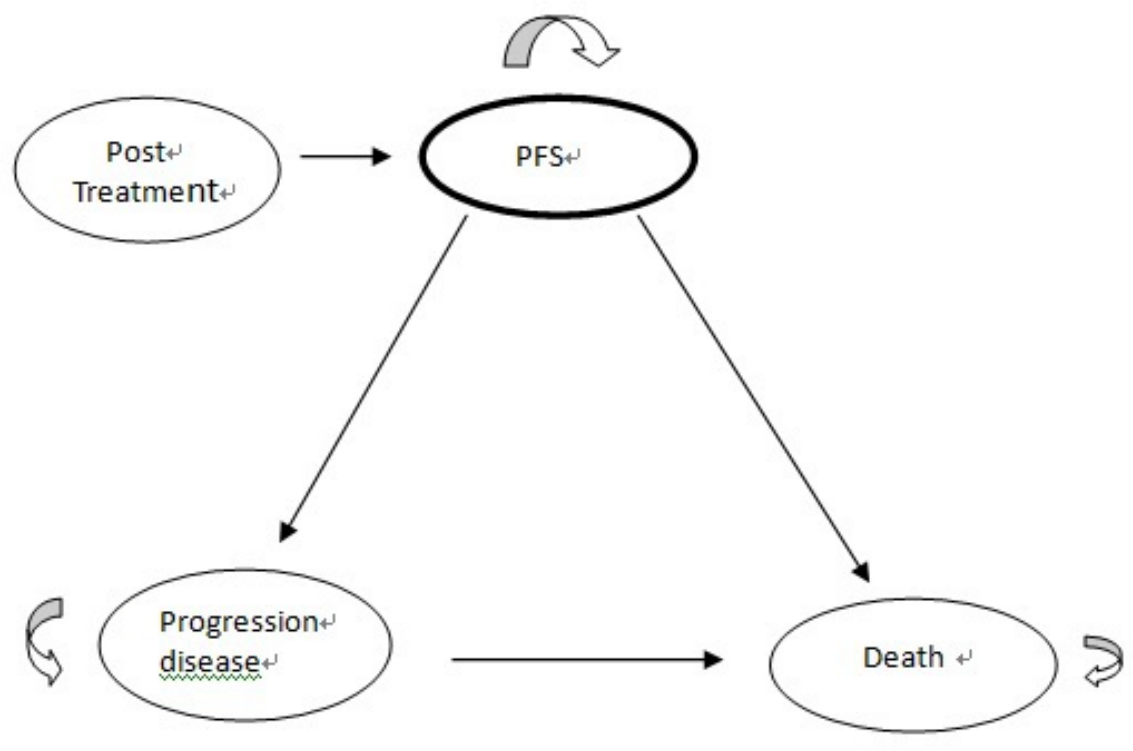

Figure 1: Markov model schema in advanced HCC. Ovals presented the differing health states. Arrows indicated pathways that can occur. Arrow returned back to the same health state and remained in that health state. 
Table 2: Parameters value in base-case and ranges in sensitivity analyses $( \pm 30 \%)$

\begin{tabular}{|c|c|c|c|}
\hline Parameters & $\begin{array}{l}\text { Base estimate } \\
\text { (3\% discount) }\end{array}$ & \begin{tabular}{|l} 
Lower- Upper \\
Limit Limit
\end{tabular} & $\begin{array}{l}\text { Assumed } \\
\text { Distribution }\end{array}$ \\
\hline \multicolumn{4}{|l|}{ Transition Probability } \\
\hline ProgToMeta for proton & 0.1295 & $0.09-0.1685$ & Beta \\
\hline ProgToDead for proton & 0.06697 & $0.047-0.08697$ & Beta \\
\hline PD To death for proton & 0.0219 & $0.015-0.029$ & Beta \\
\hline ProgToMeta1 for SBRT & 0.109 & $0.076-0.142$ & Beta \\
\hline ProgToDead1 for SBRT & 0.08299 & $0.0581-0.1079$ & Beta \\
\hline PD To death1 for SBRT & 0.0399 & $0.0279-0.0519$ & Beta \\
\hline \multicolumn{4}{|l|}{ Utility } \\
\hline PFS for proton & 0.399 & $0.279-0.519$ & Beta \\
\hline PD for proton & 0.28 & $0.196-0.476$ & Beta \\
\hline PFS1 for SBRT & 0.375 & $0.263-0.488$ & Beta \\
\hline PD1 for SBRT & 0.263 & $0.184-0.342$ & Beta \\
\hline \multicolumn{4}{|c|}{ Direct Medical Costs (US\$=32 NT) } \\
\hline cPFS for proton & 291000 & $203700-378300$ & Constant \\
\hline cPFS1 for SBRT & 219843 & $153890-285796$ & Constant \\
\hline cPD for proton & 97478 & $68235-126721$ & Constant \\
\hline cPD1 for SBRT & 141916 & 99341-184491 & Constant \\
\hline
\end{tabular}

Abbreviations: c, cost; SBRT, sterotactic body radiation therapy; PFS, progression free survival; PD, progression disease All costs presented were discounted at 3\% from the original price to adjust for the relative value of the Taiwan dollar.

\section{RESULTS}

\section{Base-case analysis}

Modeled outcomes in terms of median overall survival were consistent with the study target data. The median overall survival at 1 year reported in PBT trial and SBRT trial were $77 \%$ and $63 \%, 2$ year were and $66 \%$ and $51 \%$, respectively (Figure 2). The patient characteristics retrieved from two trials were similar, and no significant differences were found in sex, age, ECOG performance status, plasma levels of $\alpha$-fetoprotein (AFP), Barcelona Clinic Liver Cancer stages B and C, percentage of Child-

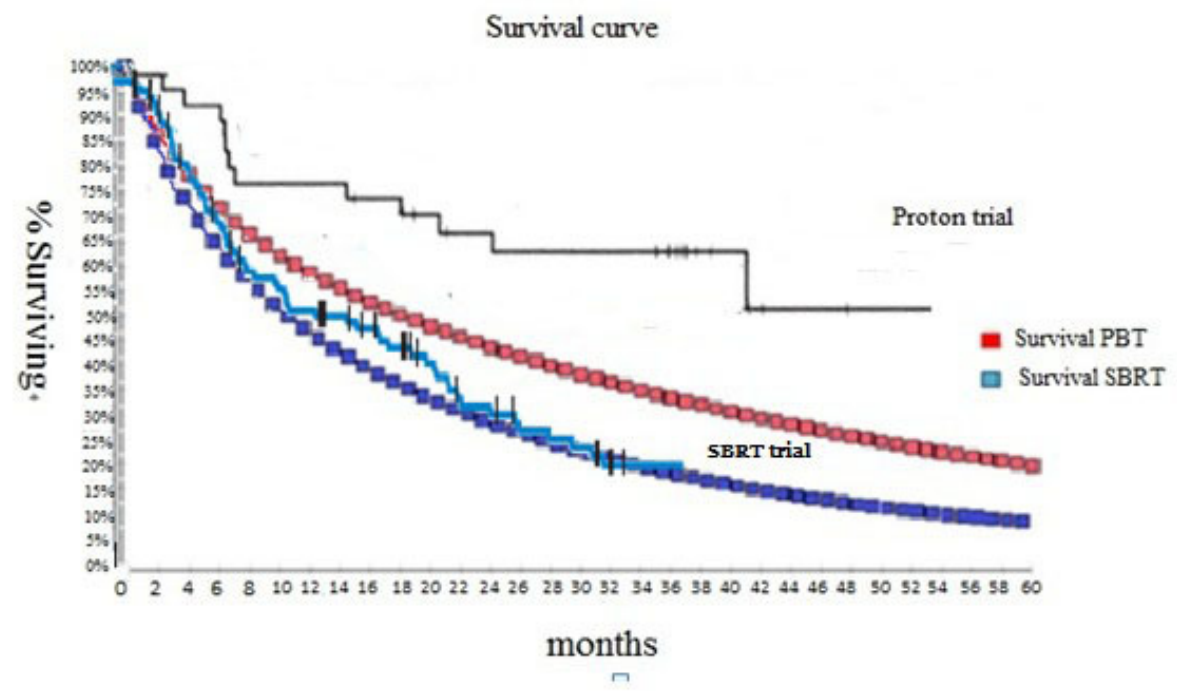

Figure 2: Modeled Kaplan- Meier Analysis of overall survival. Trials data were referred to published literature.[8, 9]. 


\section{CE Acceptability Curve}

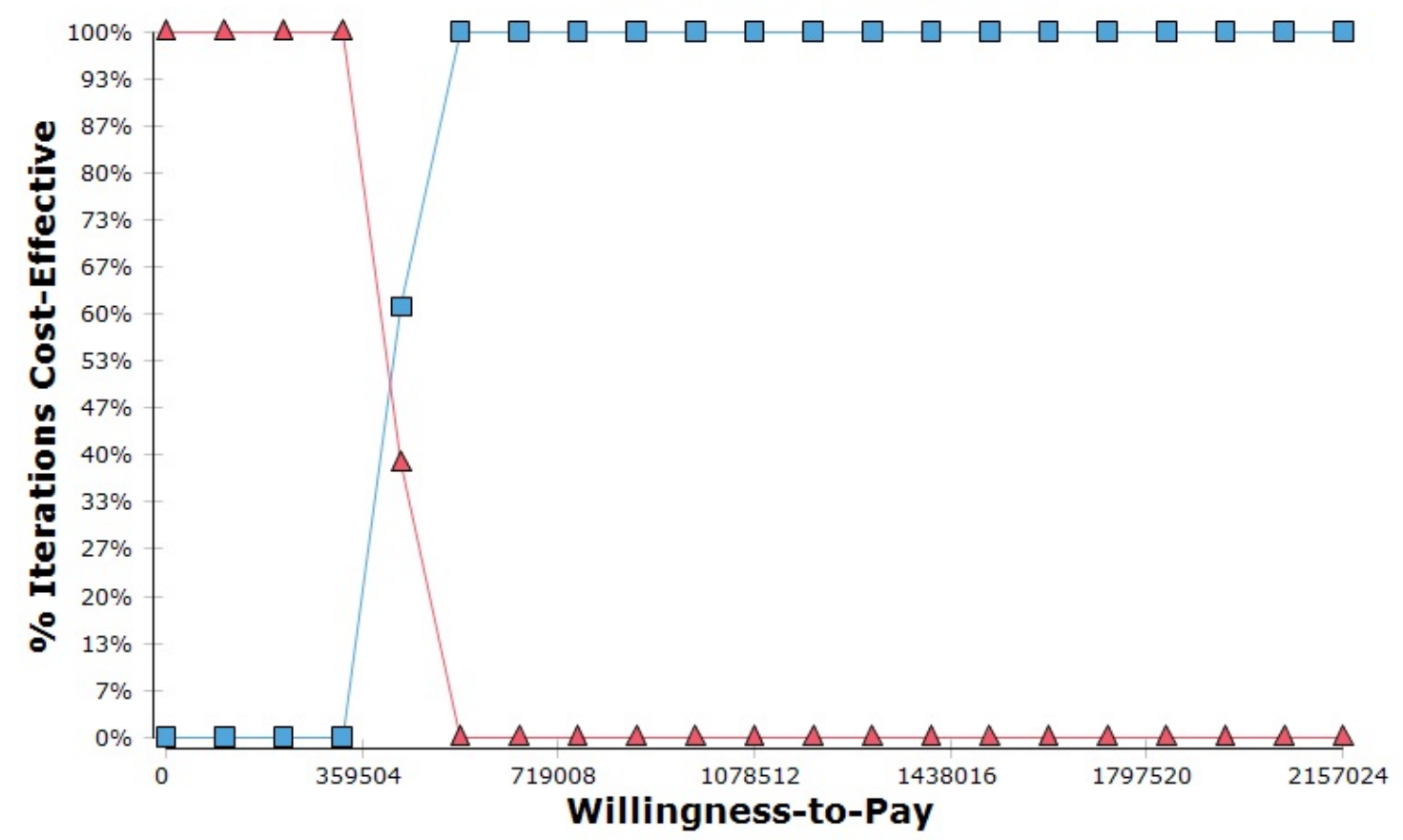

$\square$ - Proton

$\triangle$ SBRT

Figure 3a. Cost-effectiveness curve at WTP in baseocase

\section{CE Acceptability Curve}

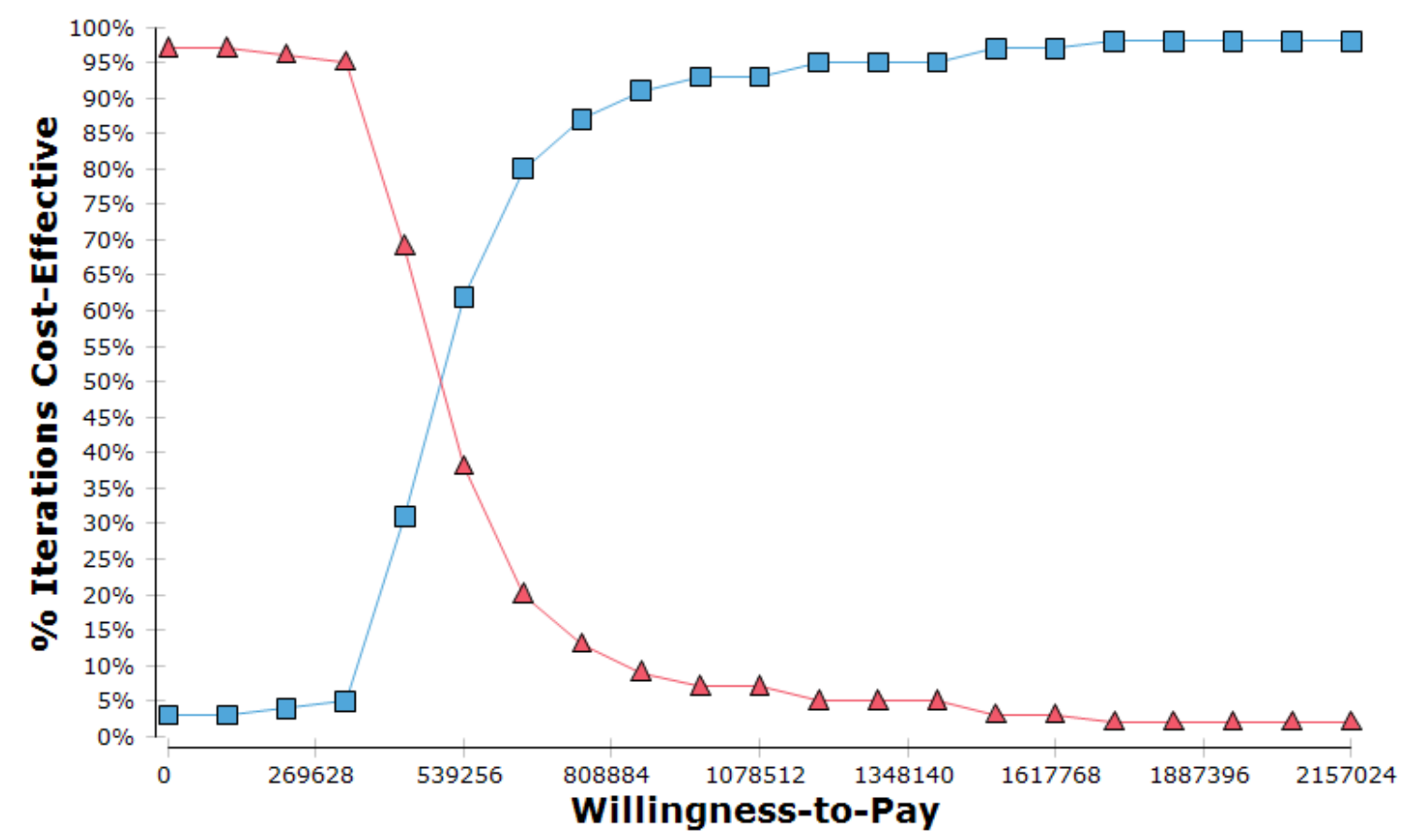

Cost-effectiveness curve at WTP in Probability sensitivity analysis

Figure 3: (Upper). Cost-effectiveness curve at WTP in base case. (Lower). CEA at WTP in PSA. 
Table 3: Baseline characteristics of the patients in the Phase II and Phase I/II trials

\begin{tabular}{|c|c|c|c|}
\hline Characteristics & Phase II proton trial & Phase I/II trial & $P$ value \\
\hline Age,years & 70 & 69.4 & 0.22 \\
\hline Male no $(\%)$ & $20(67 \%)$ & $80(78.4 \%)$ & 0.287 \\
\hline \multicolumn{4}{|l|}{ Underlying liver disease } \\
\hline Hepatitis B & $3(10 \%)$ & $39(38.2 \%)$ & 0.06 \\
\hline Hepatitis C & $26(87 \%)$ & $39(38.2 \%)$ & $<0.0001$ \\
\hline \multicolumn{4}{|l|}{ ECOG performance status $n(\%)$} \\
\hline 0 & \multirow{2}{*}{$29(97 \%)$} & \multirow{2}{*}{$85(83.3)$} & \multirow{2}{*}{0.05} \\
\hline 1 & & & \\
\hline 2 & $1(3 \%)$ & $11(10.8 \%)$ & 0.81 \\
\hline \multicolumn{4}{|l|}{ Child-Pugh class, no (\%) } \\
\hline A & $20(67 \%)$ & $102(100 \%)$ & $<0.0001$ \\
\hline B & $10(33 \%)$ & $0(0 \%)$ & \\
\hline $\mathrm{C}$ & $67(65.7 \%)$ & $0(0 \%)$ & \\
\hline Tumor Size, median & $45 \mathrm{~mm}$ & $72 \mathrm{~mm}$ & \\
\hline \multicolumn{4}{|l|}{ Biochemical analysis } \\
\hline $\operatorname{Albumin}(\mathrm{g} / \mathrm{dl})$ & 0 & 4.0 & \\
\hline Total bilirubin ( $\mathrm{mg} / \mathrm{dl})$ & 0 & 1.3 & \\
\hline Alpha-fetoprotein & $<300 \mathrm{ng} / \mathrm{ml}$ & $163 \mathrm{nmol} / \mathrm{L}$ & \\
\hline \multicolumn{4}{|l|}{ Previous therapy } \\
\hline Local ablation /TACE & $11(37 \%)$ & $22(21.6 \%)$ & 0.368 \\
\hline Macrovascular invasion ( no,\%) & $12(40 \%)$ & $20(49 \%)$ & 0.63 \\
\hline
\end{tabular}

Abbreviations: ECOG, Eastern Cooperative Oncology Group; BCLC, Barcelona Clinic Liver Cancer staging system; TACE, transarterial chemoembolization; RFA, radiofrequency ablation; PEI, percutaneous ethanol injection.

\section{NMB v. Willingness-to-Pay}

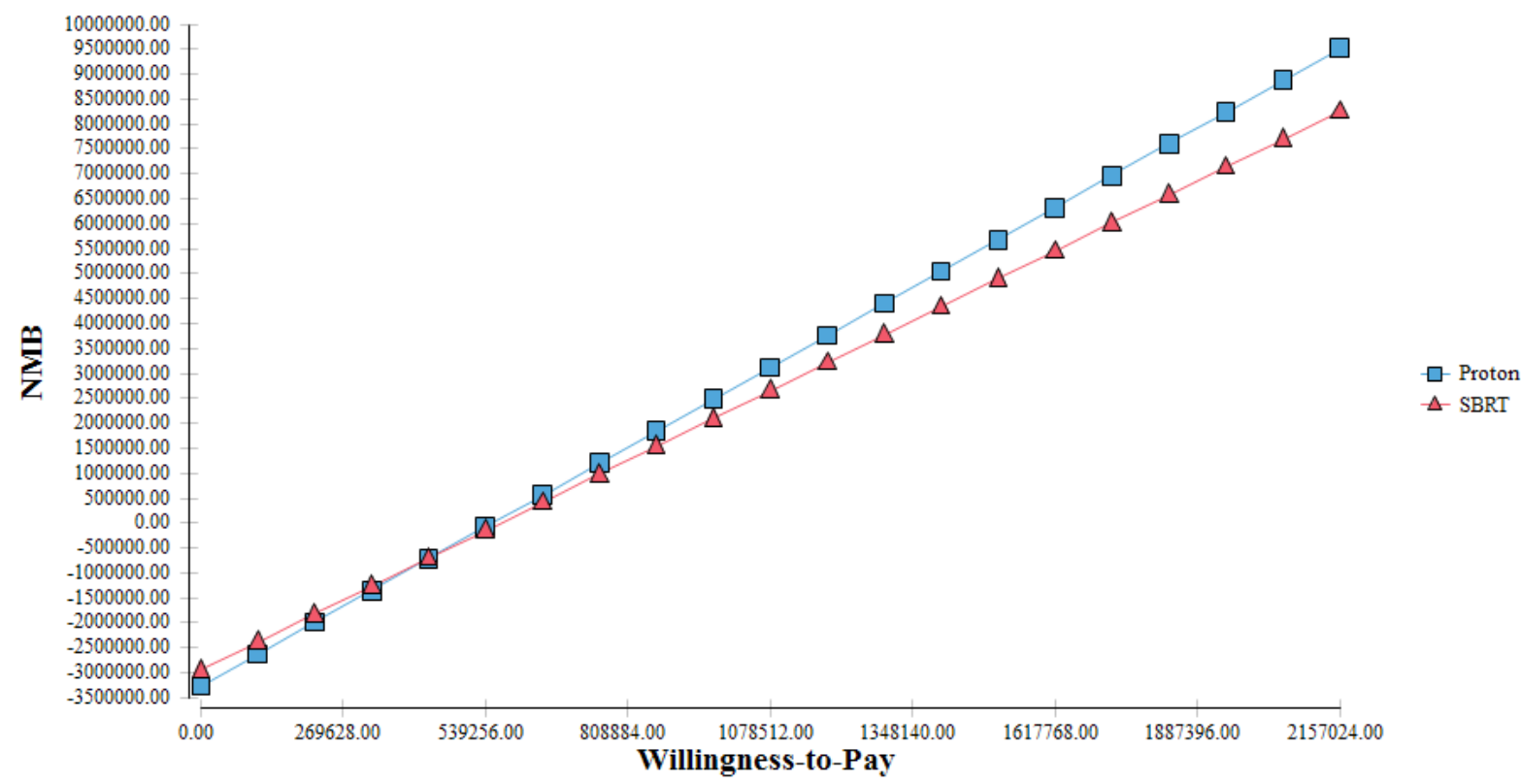

Figure 4: NMB varying the threshold value from NT\$ 0.00 to NT\$2,157,024. 
Table 4: Tornado sensitivity analysis-ICER report

\begin{tabular}{|l|c|l|l|l|l|l|l|}
\hline $\begin{array}{l}\text { VARIABLE } \\
\text { NAME }\end{array}$ & VARIALE RANGE & LOW VALUE & HIGH VALUE & SPREAD & SPREAD SQR & $\begin{array}{l}\text { RISK } \\
\text { PCT }\end{array}$ & $\begin{array}{l}\text { CUMUL } \\
\text { PCT }\end{array}$ \\
\hline uPD & 0.196 to 0.476 & -3834190.96694 & 634945.18245 & 4469136.14939 & 19973177921776.06 & 0.19003 & 0.33323 \\
\hline uPFS & 0.279 to 0.519 & -1780405.66472 & 1448835.01484 & 3229240.67956 & 10427995366529.27 & 0.09921 & 0.14257 \\
\hline uPD1 & 0.184 to 0.342 & -1324462.00957 & 1684826.81114 & 3009288.82071 & 9055819206466.062 & 0.08616 & 0.47922 \\
\hline cPFS & 203700.0 to 378300.0 & -422990.16247 & 1452808.99214 & 1875799.15461 & 3518622468452.824 & 0.03348 & 0.04333 \\
\hline uPFS1 & 0.263 to 0.488 & 297633.7112 & 1954325.66909 & 1656691.95789 & 2744628243332.1616 & 0.02611 & 0.39306 \\
\hline cPD1 & 99341.0 to 184491.0 & -233531.45512 & 1263350.28479 & 1496881.7399 & 2240654943250.1396 & 0.02132 & 0.36158 \\
\hline
\end{tabular}

Remarks: uPD, uPFS : utility of patients treated with proton in stable states and progressive state; uPD1and uPFS1, utility of patients treated with SBRT in stable states and progressive state; cPFS, direct medical cost for proton in progression state; cPD1, direct medical cost for SBRT in stable state.

Pugh class A liver function, or tumor size. Patients with underlying hepatitis $\mathrm{C}$ and Child-Pugh class A were significantly different between the two trials (Table 3 ). The incidence of grade $3 / 4$ toxicity was $30 \%$ and $34.3 \%$ for PBT and SBRT, respectively.

The direct health care medical costs per month by disease stage and treatment group are shown in Table 1. PBT had the highest cost for each patient in the stable stage (NT\$300,000), whereas the SBRT group experienced the highest cost in the progressive stage (NT\$146,305) because of high treatment costs for grade 3-4 toxicity. PBT resulted in an additional 2.61 QALY gains at an incremental cost of NT\$557,907. The ICER for PBT versus SBRT was NT\$213,354 per QALY gained.

\section{Sensitivity analyses}

A tornado diagram illustrated the results of one-way sensitivity analysis that the highly sensitive 6 parameters were the utility of patients treated with PBT or SBRT in stable and progressive states as well as the direct medical costs in both states. The high value for utility of patients treated with PBT in stable and progressive states results in proton being the preferred strategy (Table 4).

The Monte Carlo simulation demonstrated that the probability of PBT and SBRT being cost-effective was $97 \%$ and $4 \%$, respectively, at the WTP threshold of NT\$2,157,024 (Figure 3). The more positive NMB values for PBT compared to SBRT by varying the WTP threshold indicated that PBT was likely to be cost-effective at the specific WTP of Taiwan (Figure 4).

\section{DISCUSSION}

This study presents an assessment of the potential clinical benefits and cost-effectiveness of PBT compared with SBRT in the treatment of inoperable advanced HCC. The literature on SBRT for small $\mathrm{mHCC}$ is extensive, but the information on the consequences of proton therapy for $\mathrm{mHCC}$ patients is very little. In particular, the information on cost-effectiveness data is limited.

Treatment of the base case population of $\mathrm{mHCC}$ patients resulted in an incremental cost per QALY gained of about NT\$ 557, 907. The results also indicated that the incremental cost-effectiveness ratio could be considerably lower if patients at higher risk of severe toxicity were chosen for the treatment. The cost- effectiveness is thus highly dependent on the possibility of selecting appropriate risk patients for the therapy. Our results are consistent with other previous cost-effectiveness and the recent published systematic review of CEA studies, they reported that $\mathrm{PBT}$ offers promising cost-effectiveness for several cancers based on careful patient selection [21-22].

To determine whether a treatment is regarded as cost-effective or not is often depended on the threshold value for the cost effectiveness ratio. The WTP thresholds based on per capita gross domestic product (GDP), has been promoted by the World Health Organization's Choosing Interventions in 2001 [23-24] and has been used as the threshold value per QALY gained in a number of recent cost-effectiveness studies. The WTP thresholds are higher than our base case result, which indicates that proton therapy used for inoperable advanced HCC patients with a risk of developing radiation-induced liver disease and with a lower radiation tolerance. Therefore, proton therapy is cost-effective for high-risk patients.

We tested the stability of the results with various sensitivity analyses, which showed that the results were robust. Several key parameters are impacted on the costeffectiveness results. One is the direct medical cost of treating an individual patient. The new radiation technique may result in higher or lower healthcare expenditure for each patient treated. Although the direct medical costs of the SBRT and PBT paid as a treatment package which include the cost of physician office visits, radiation therapy treatment items (such as radiation fraction, computerized treatment planning, dosimetry and vertification film, new screening or diagnosis capacity that allows more targeted treatment etc), other health care costs for hospital days, treatment of severe toxicities and routine follow-up clinic visit are not included in the package. Therefore, the direct medical cost in progression state was higher in SBRT than PBT. Another parameter is the reduction of utility of patients in each healthcare state by $30 \%$ and $34.3 \%$ severe toxicity rates caused by the PBT and SBRT. The reduced utility may effect on patients quality of life. Finally, the tumor size is also a parameter impacted on the clinical 
outcomes, which presented in terms of tumor control rate or overall survival. The median size of target tumor treated was larger in SBRT than that in PBT $(7.2 \mathrm{~cm}$ vs $4.5 \mathrm{~cm}$ ). Therefore, the overall survival reported in the PBT trial was longer than that in the SBRT trial (31 months vs 17 months). The longer survival will incur the increase of the direct medical costs used in patient's life expectancy.

Since years of 2006, SBRT can be accepted as a safe modality for small tumor $(<5 \mathrm{~cm}$ size $)$ in many countries [25-27]. Inoperable large $\mathrm{mHCC}$ remains a therapeutic challenge, but modern radiation modalities are emerging for local therapy. Recently, SBRT and PBT was reported with a high local control rate for inoperable large $\mathrm{HCC}(>$ $5 \mathrm{~cm}$ ) from a single institution [10-12, 28-29]. However, these modern radiation therapies are associated with high economic costs. In particular, proton therapy is today only available in a limited center worldwide. The capital investment and operating facilities are large [30] and information about the potential clinical benefits and cost-effectiveness of the therapy is important for future decisions about reimbursement for new technology. Although the analyses presented in this study were based on only one center uncertain estimates, the result is still an evidence of the potential cost-effectiveness of proton therapy for incurable cancer which thus would support reimbursement and investments in this technology. The decision makers at our BNHI need to be aware of the economic burden of new technologies to assess the costeffectiveness, balance the increasing healthcare budget, and meet expectations from patients and clinical practice.

This study has several limitations worth mentioning. First, our country currently has only one center for PBT. The lack of empirical comparative evidence to support the clinical data from two clinical trials imputed in our model may slightly influence the accuracy of the model. Second, the percentage of extra-hepatic spread and vascular invasion in patients was higher in the PBT trial than the SBRT trial. This may have some influence on the outcomes in the PBT group in terms of overall survival and progression-free survival. Third, the percentage of Child-Pugh class B liver function was higher among patients recruited in the PBT trial than the SBRT trial. This difference may also influence utility. However, the variation and wide ranges of parameters in the sensitivity analyses offset these limitations and the results are robust.

\section{Author contributions}

Leung HW contributed to idea creation, expert opinion, systematic review, and data check. Chan AC contributed to study design, economic software running, and data analysis.

\section{CONFLICTS OF INTEREST}

We did not have any conflict of interest.

\section{REFERENCES}

1. World Health Organization (WHO). http://www.who.int/ mediacentre/factsheets/fs297/en/. Accessed 13 Feb 2016.

2. Taiwan cancer registry. http://tcr.cph.ntu.edu.tw/main. php?Page=N2. Accessed 13 Feb 2016.

3. Torre LA, Bray F, Siegel RL, Ferlay J, Lortet-Tieulent J, Jemal A. Global cancer statistics, 2012. CA Cancer J Clin. 2015; 65:87-108.

4. Bruix J, Sherman M, and Practice Guidelines Committee, American Association for the Study of Liver Diseases. Management of hepatocellular carcinoma. Hepatology. 2005; 42:1208-36.

5. Oliveri RS, Wetterslev J, Gluud C. Transarterial (chemo) embolisation for unresectable hepatocellular carcinoma. Cochrane Database Syst Rev. 2011; 3:CD004787.

6. Feng M, Ben-Josef E. Radiation therapy for hepatocellular carcinoma. Semin Radiat Oncol. 2011; 21:271-77.

7. Stillwagon GB, Order SE, Guse C, Klein JL, Leichner PK, Leibel SA, Fishman EK. 194 hepatocellular cancers treated by radiation and chemotherapy combinations: toxicity and response: a Radiation Therapy Oncology Group Study. Int J Radiat Oncol Biol Phys. 1989; 17:1223-29.

8. Bujold A, Massey CA, Kim JJ, Brierley J, Cho C, Wong RK, Dinniwell RE, Kassam Z, Ringash J, Cummings B, Sykes J, Sherman M, Knox JJ, Dawson LA. Sequential phase I and II trials of stereotactic body radiotherapy for locally advanced hepatocellular carcinoma. J Clin Oncol. 2013; 31:1631-39.

9. Kawashima M, Furuse J, Nishio T, Konishi M, Ishii H, Kinoshita T, Nagase M, Nihei K, Ogino T. Phase II study of radiotherapy employing proton beam for hepatocellular carcinoma. J Clin Oncol. 2005; 23:1839-46.

10. Jang WI, Kim MS, Bae SH, Cho CK, Yoo HJ, Seo YS, Kang JK, Kim SY, Lee DH, Han CJ, Kim J, Park SC, Kim SB, et al. High-dose stereotactic body radiotherapy correlates increased local control and overall survival in patients with inoperable hepatocellular carcinoma. Radiat Oncol. 2013; 8:250.

11. Scorsetti M, Comito T, Cozzi L, Clerici E, Tozzi A, Franzese C, Navarria P, Fogliata A, Tomatis S, D'Agostino G, Iftode C, Mancosu P, Ceriani R, Torzilli G. The challenge of inoperable hepatocellular carcinoma (HCC): results of a single-institutional experience on stereotactic body radiation therapy (SBRT). J Cancer Res Clin Oncol. 2015; 141:1301-09.

12. Que JY, Lin LC, Lin KL, Lin CH, Lin YW, Yang CC. The efficacy of stereotactic body radiation therapy on huge hepatocellular carcinoma unsuitable for other local modalities. Radiat Oncol. 2014; 9:120.

13. Murray CJ, Evans DB, Acharya A, Baltussen RM. Development of WHO guidelines on generalized costeffectiveness analysis. Health Econ. 2000; 9:235-51.

14. Taiwan Economic Outlook. www.focus-economics.com/ 
countraes/taiwan. Accessed 18 Oct, 2016.

15. Directorate-General of Budget, Accounting and Statistics Ministry of Foreign Affairs, Republic of China. (Taiwan). http://taiwantoday.tw/ct.asp?xItem=239566\&ctNode $=435$. Accessed 24 Sept 2016.

16. Keeler E. Decision trees and Markov models in costeffectiveness research. Value in Health Care; 1995. pp. 185-205.

17. Zhou J, Zhao R, Wen F, Zhang P, Tang R, Chen H, Zhang J, Li Q. Economic evaluation study (CHEER-compliant): cost-effectiveness analysis of RAS screening for treatment of metastatic colorectal cancer based on the CALGB 80405 trial. Medicine (Baltimore). 2016; 95:e3762.

18. Cucchetti A, Piscaglia F, Cescon M, Colecchia A, Ercolani G, Bolondi L, Pinna AD. Cost-effectiveness of hepatic resection versus percutaneous radiofrequency ablation for early hepatocellular carcinoma. J Hepatol. 2013; 59:300 07.

19. Drummond MF, Sculpher MJ, Torrance GW. Methods for the Economic Evaluation of Health Care Programs. Oxford, England: Oxford University Press; 2005.

20. Net benefits calculations, TreeAge Pro 2015 User's Manual. TreeAge Software, Inc; 2015.

21. Lundkvist J, Ekman M, Ericsson SR, Isacsson U, Jönsson B, Glimelius B. Economic evaluation of proton radiation therapy in the treatment of breast cancer. Radiother Oncol. $2005 ; 75: 179-85$.

22. Lundkvist J, Ekman M, Ericsson SR, Jönsson B, Glimelius B. Cost-effectiveness of proton radiation in the treatment of childhood medulloblastoma. Cancer. 2005; 103:793-801.

23. Choosing interventions that are cost-effective. Geneva: World Health Organization; 2014. Available from: http:// www.who.int/choice/en/ [cited 2014 Nov 27].
24. Nimdet $K$, Chaiyakunapruk N, Vichansavakul K, Ngorsuraches S. A systematic review of studies eliciting willingness-to-pay per quality-adjusted life year: does it justify CE threshold? PLoS One. 2015; 10:e0122760.

25. Tse RV, Hawkins M, Lockwood G, Kim JJ, Cummings B, Knox J, Sherman M, Dawson LA. Phase I study of individualized stereotactic body radiotherapy for hepatocellular carcinoma and intrahepatic cholangiocarcinoma. J Clin Oncol. 2008; 26:657-64.

26. Huertas A, Baumann AS, Saunier-Kubs F, Salleron J, Oldrini G, Croisé-Laurent V, Barraud H, Ayav A, Bronowicki JP, Peiffert D. Stereotactic body radiation therapy as an ablative treatment for inoperable hepatocellular carcinoma. Radiother Oncol. 2015; 115:21116.

27. Hijazi H, Campeau MP, Roberge D, Donath D, Lapointe R, Vandenbroucke-Menu F, Taussky D, Boudam K, Chan G, Bujold A, Delouya G. Stereotactic Body Radiotherapy for Inoperable Liver Tumors: Results of a Single Institutional Experience. Cureus. 2016;8:e935.

28. Kimura K, Nakamura T, Ono T, Azami Y, Suzuki M, Wada H, Takayama K, Endo H, Takeyama T, Hirose K, Takai Y, Kikuchi Y. Clinical results of proton beam therapy for hepatocellular carcinoma over 5cm. Hepatol Res. 2017. https://doi.org/10.1111/hepr.12874.

29. Sugahara S, Oshiro Y, Nakayama H, Fukuda K, Mizumoto M, Abei M, Shoda J, Matsuzaki Y, Thono E, Tokita M, Tsuboi K, Tokuuye K. Proton beam therapy for large hepatocellular carcinoma. Int J Radiat Oncol Biol Phys. 2010; 76:460-66.

30. Verma V, Shah C, Rwigema JC, Solberg T, Zhu X, Simone $\mathrm{CB}$ 2nd. Cost-comparativeness of proton versus photon therapy. Chin Clin Oncol. 2016; 5:56. 